\title{
Experimental Investigations on Mechanical Properties of AZ31/Eggshell Particle-Based Magnesium Composites
}

\author{
N. Ramanujam, ${ }^{1}$ S. Muthukumaran, ${ }^{2}$ B. Nagesawara Rao ${ }^{\circ},{ }^{3}$ M. Ramarao, ${ }^{4}$ \\ Amol L. Mangrulkar, ${ }^{5}$ K. S. Ashraff Ali, ${ }^{6}$ L. Pugazhendhi, ${ }^{7}$ and Mebratu Markos $\mathbb{D}^{8}$ \\ ${ }^{1}$ Department of Mechanical Engineering, E.G.S. Pillay Engineering College, Nagapattinam 611002, Tamilnadu, India \\ ${ }^{2}$ Department of Mechanical Engineering, University College of Engineering Panruti, Panruti, Tamil Nadu, India \\ ${ }^{3}$ Department of Mechanical Engineering, VFSTR, Vadlamudi, Guntur 52213, Andhra Pradesh, India \\ ${ }^{4}$ Department of Mechanical Engineering, Bharath Institute of Higher Education and Research, Chennai 600073, \\ Tamilnadu, India \\ ${ }^{5}$ Department of Mechanical Engineering, Rajiv Gandhi Institute of Technology, Mumbai 400053, India \\ ${ }^{6}$ Department of Mechanical Engineering, C. Abdul Hakeem College of Engineering \& Technology, Vellore 632509, \\ Tamil Nadu, India \\ ${ }^{7}$ Department of Mechanical Engineering, Chennai Institute of Technology, Chennai 600059, Tamilnadu, India \\ ${ }^{8}$ Department of Mechanical Engineering, College of Engineering, Wolaita Sodo University, Ethiopia
}

Correspondence should be addressed to Mebratu Markos; mebratumarkos@wsu.edu.et

Received 1 October 2021; Accepted 15 December 2021; Published 30 January 2022

Academic Editor: P. Ganeshan

Copyright $\odot 2022$ N. Ramanujam et al. This is an open access article distributed under the Creative Commons Attribution License, which permits unrestricted use, distribution, and reproduction in any medium, provided the original work is properly cited.

Magnesium (AZ31) is an excellent choice for a bionic implant. To enhance biocompatibility, the hardest graphene nanoparticles were reinforced with biocompatible materials. In this paper, biocompatibility composite material is produced by stir-casting nanoshell particles reinforced with various weight percentages $(0,1,2,3$, and 4 wt. percent) of AZ31 magnesium alloy. To understand the mechanical properties of the composite material, results of which are compared to the base alloy (AZ31) are used. The study mentioned how AZ31 magnesium alloy, reinforced with reinforcing particles, may be used to create implant-related human bone materials. Magnesium alloy reinforced with reinforcing particles is described in the study.

\section{Introduction}

Magnesium has excellent biocompatibility and modulus of elasticity in line with the human bone. Inorganic-stage calcium-containing crystals are embedded in the bone, increasing the tissue's sensitivity to normal stresses. Due to pathology and desorption, bone tissue breaks. Metals utilized for clinical purposes are found in the manufacturing process of bone fixation devices [1]. Magnesium is in high demand in every sector involved in the design and manufacture of automobiles, aircraft, and diverse engineering to meet those industry's needs. However, further advancement will be necessary if this technological evolution is to continue. MMC is a possible solution. Fibres or particulate of a ceramic material, i.e., silicon carbide or graphite, are usually present in metal matrix composites to reinforce the lowdensity material, i.e., aluminium or magnesium. Specifically, higher stiffness, operating temperature, wear resistance, and customizable properties can be found in these materials. AZ31 magnesium alloys have the opportunity to explore as light alloys for replacing some conventional structural materials in cars and trucks, locomotives, and general aviation. Using particulate magnesium matrix composites to make isotropic materials with improved mechanical properties is a favourable fabrication process (MMCs). Each of these variables is beneficial in increasing the mechanical properties of MMCs. Mg alloy in the AZ series has properties of cost effectiveness, density friendliness, and good mechanical properties, as well as cast ability [2]. The resulting thermomechanical processed precipitates of Mg17Al12 
improve the mechanical properties. In addition, AZ Mg alloy incorporates particle reinforcements (which causes a higher strengthening efficiency) and thus incorporates reinforcements $[3,4]$. The AZ Mg alloy has a significant increase in the amount of aluminium in its semisolid region, making it appropriate for semisolid casting. Developing new lightweight materials from recycled materials will be critical to sustainable development [5-7]. When there are Ti and SS alloys limiting the supply, magnesium can be a suitable alternative. Magnesium is exceptional in having a high level of strength, load-bearing capacity, biocompatibility, toxicity, and wide abundance in the earth's crust, water, and the human body and a modulus of elasticity that matches the bone $[8,9]$. This is why the bone is more elastic than normal; thus, it protects the implant and bone better.

Additionally, Mg-based materials reduce the trauma the host patient experiences while also benefiting the host [10-14]. This is significant because even though it is possible for $\mathrm{Mg}$ to be absorbed into the human body and excreted without triggering an inflammatory response, this does not occur if $\mathrm{Mg}$ is consumed or injected. To make magnesium an attractive temporary implant, it is necessary to use conventional materials with these two features [15-19]. There are various requirements for materials that use $\mathrm{Mg}$; they must meet them all to function as an equivalent replacement for the materials they replace. The importance of having important properties such as biocompatibility and low toxicity and other undesirable side effects over the service life cannot be stressed enough [20]. To obtain novel Mg-based materials with enhanced mechanical and corrosion responses, biocompatible alloying elements/reinforcements are required [21, 22]. Magnesium, in its original form, has few disadvantages, such as flexibility and corrosion resistance, in aqueous environments [23, 24]. Ball milling is a mechanical method for grinding particles into small particulates. Conventionally, the particles are usually cracked apart by solvent molecules; however, the reactants are separated apart by mechanical stresses in ball milling.

Methods used in the past have included the use of $\mathrm{Al}_{2} \mathrm{O}_{3}$, $\mathrm{Y}_{2} \mathrm{O}_{3}, \mathrm{SiC}$, and CNT nanoparticles in various $\mathrm{Mg}$-based composites (also known as carbon nanotubes). Also, recent studies [25-29] show that increasing magnesium's strength and ductility at the nanoscale by using ceramic reinforcements is possible. Because AZ31 alloy is so widely used in engineering applications, it has been paid a lot of attention [30]. From a survey of the relevant literature, the researchers found that very little research has been conducted to study the mechanical behaviour of nanometer-sized particulate or fibre hybrid-reinforced metal matrix composites. Results obtained from experiments with AZ31 magnesium matrix composites reinforced with submicron-SiC particulates showed that the mechanical properties were improved significantly. Xiang et al. [4] proceeded with the stir casting of AZ31 and discussion of mechanical characterization of the $\mathrm{SiC}$ particles included. The studies found that increasing the reinforcing particle from titanium dioxide, also called titanium(III) oxide, increases ultimate tensile strength, yield strength, and elastic modulus, along with a decrease in grain size [31]. Eggshell is a low-cost, abundant source of calcium, one of the best reinforcement options, which can be derived from chicken aviculture. Bone flours and oyster shells contain toxic elements such as $\mathrm{Cd}, \mathrm{Al}$, and $\mathrm{Hg}$, and these toxins cause diseases in people, making bone flours and oyster shells less useful for medical use. The role of calcium in promoting bone mineralization aids in bone remodelling [32]. Eggshell having a lower density and greater stability has been superior to calcium carbonate, industrially prepared. It has recently been discovered that eggshells enhance the refining and strengthening of grain size and strength in the $\mathrm{Al}$ and Mg matrix. Magnesium alloy AZ31 was synthesized by stirring in water, and this solution was applied to small eggshell-sized nanoeggshell particles [32-34]. Researchers are conducting a series of experiments in order to determine the effect of nanoeggshell particles on the mechanical properties of magnesium alloy AZ31 in which the particles are also incorporated.

\section{Materials and Methods}

Magnesium is an important metal used in numerous industries, including electronics, automobiles, and aerospace. The composition of magnesium alloy AZ31 is listed in Table 1. Ball milling was used to reduce the average size of the eggshell powder $(15-35 \mathrm{~nm})$ to a finer nanosize that is just above the sub-nanosize range. The particle size of the product dropped dramatically after ball milling. The powder was ball-milled for 15 hours and then refined for 20 hours, which refined the powder to an average particle size of less than $75 \mathrm{~nm}$ and a range of $15-35 \mathrm{~nm}$. The overall size of the ball mill did not change as the 40-hour ball milling time remained constant. This is why the synthesis of the composite materials required a total of 20 hours of eggshell powder that had been ball-milled. Powdered eggshells did not have detectable peaks other than calcium carbonate after the milling process. After ball milling, no impurities or additional secondary phases were found. Magnesium's biocompatible feature is increased by utilizing nanoeggshell particles (15-35 $\mathrm{nm}$ size), which improve the material's mechanical properties. Magnesium alloy AZ31's distinct composition details are shown in Table 2.

The density data from the samples that were developed are documented in Table 3. To obtain theoretical density, the rule of mixtures method was used.

The experimental density of magnesium alloy AZ31 used in the experiment is $2.231 \mathrm{~g} / \mathrm{cc}$. In order to measure experimental densities, the nanoeggshell particles (wt. percentages of $1,2,3$, and 4) were added. This increased the measured densities to $2.568,2.765,2.963$, and $3.123 \mathrm{~g} / \mathrm{cc}$, respectively. A study following up on this led to a later discovery of rising porosity levels in the samples. Near-dense materials are acceptable under certain porosity limits, which is what makes this trend in porosities acceptable. The lower porosity levels primarily attributed to our control of extrusion parameters and avoidance of air entrapment in the molten slurry during the stirring process occur because of our advanced control techniques. Promotion of nanoeggshell particle reinforcement is made easier because the molten slurry in the steel mould is rendered incapable of 
TABLe 1: Various chemical elements available in magnesium alloy AZ31.

\begin{tabular}{lccccccc}
\hline Elements & Aluminium & Zinc & Manganese & Silicon & Ferrous & Calcium & Magnesium \\
\hline Contribution (\%) & 3.3 & 0.83 & 0.31 & 0.03 & 0.002 & 0.0023 & Ball \\
\hline
\end{tabular}

TABLE 2: Composition details of the composite specimens.

\begin{tabular}{lcc}
\hline Specimen identification & Wt. \% of magnesium alloy AZ31 & Wt. \% of nanoeggshell particles \\
\hline MG0 & 100 & 0 \\
MG1 & 99 & 1 \\
MG2 & 98 & 2 \\
MG3 & 97 & 3 \\
MG4 & 96 & 4 \\
\hline
\end{tabular}

TABLE 3: Density and porosity values of the samples.

\begin{tabular}{lccc}
\hline Composition & Theoretical density $(\mathrm{g} / \mathrm{cc})$ & Measured density $(\mathrm{g} / \mathrm{cc})$ & Porosity \\
\hline MG0 & 2.231 & 2.228 & 0.1346 \\
MG1 & 2.568 & 2.561 & 0.2733 \\
MG2 & 2.765 & 2.757 & 0.2902 \\
MG3 & 2.963 & 2.951 & 0.4066 \\
MG4 & 3.123 & 3.101 & 0.7094 \\
\hline
\end{tabular}

supporting itself before the slurry is applied, so the particles are more uniformly distributed, and the occurrence of porosity is avoided.

\section{Experimental Procedure}

Stir casting (Figure 1) was used to make the AZ31 magnesium metal matrix composite. Once the furnace was hot enough, the ingot of magnesium was put in. Because magnesium is highly flammable, a gas that is both nonflammable and safe to breathe was continuously supplied to the furnace as an atmosphere. To prevent the egg white from becoming sticky, the nanoeggshell particles are preheated to $350^{\circ} \mathrm{C}$ before the addition of magnesium alloys. Magnesium must be heated to $750^{\circ} \mathrm{C}$ in the crucible before it is used to raise the temperature of the heating element to $450^{\circ} \mathrm{C}$. The procedure involves mixing the eggshell particles with molten magnesium in the crucible furnace and then stirring the mixture for 15 minutes using an electric stirrer. The metal has reached a solidified state when it is naturally heated by convection and then poured into a fixed, large iron die, $150 \mathrm{~mm} \times 150 \mathrm{~mm} \times 25 \mathrm{~mm}$ in size. Figure 2 reveals the impact tester. The impact sample prepared by the ASTM standard is shown in Figure 3.

\section{Results and Discussion}

4.1. Tensile Strength. In order to investigate the elasticity and ultimate strength of the material, the tensile test was performed according to ASTM-E32 standards. Every time the materials were reinforced, a specified amount was cut and machined at three different locations according to ASTM standards. The reinforced composite was built to an approximate $34 \%$ construction, and the calculated and graphed averages were compared to the testing on a UTM machine. As reinforcement was added, tensile strength increased gradually, as illustrated in Figure 4. Strength increases

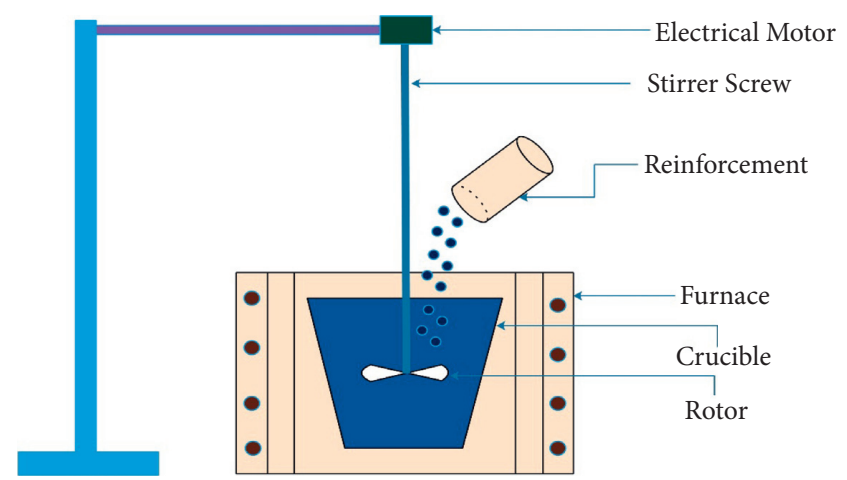

FIGURE 1: Experimental setup of the stir-casting technique.

gradually with the increasing base magnesium alloy content to 80.73 percent. A pie chart displaying the percentage elongation of the composite is shown in Figure 5. The elongation increased at a much higher rate than the AZ31 alloy.

4.2. Young's Modulus. Figure 6 shows the variation in Young's modulus for all composite specimens. With nanoeggshell particles' content, Young's modulus of the MG0 composite sample is around $71 \mathrm{GPa}$, but it slightly increased to $83 \mathrm{GPa}$ for MG4 composite specimens (4 wt. percent nanoeggshell particles).

Young's modulus depends on the orientation of nanoeggshell particles when being loaded. When nanoeggshell particles are positioned parallel to the loading direction, Young's modulus variation will be high. Conversely, when they are positioned perpendicular to the loading direction, the variation will be low. To get a medium value, roll a random number to find the orientation. As reported by this study, the milling and stir-casting techniques used in the current investigation could have caused nanoeggshell 


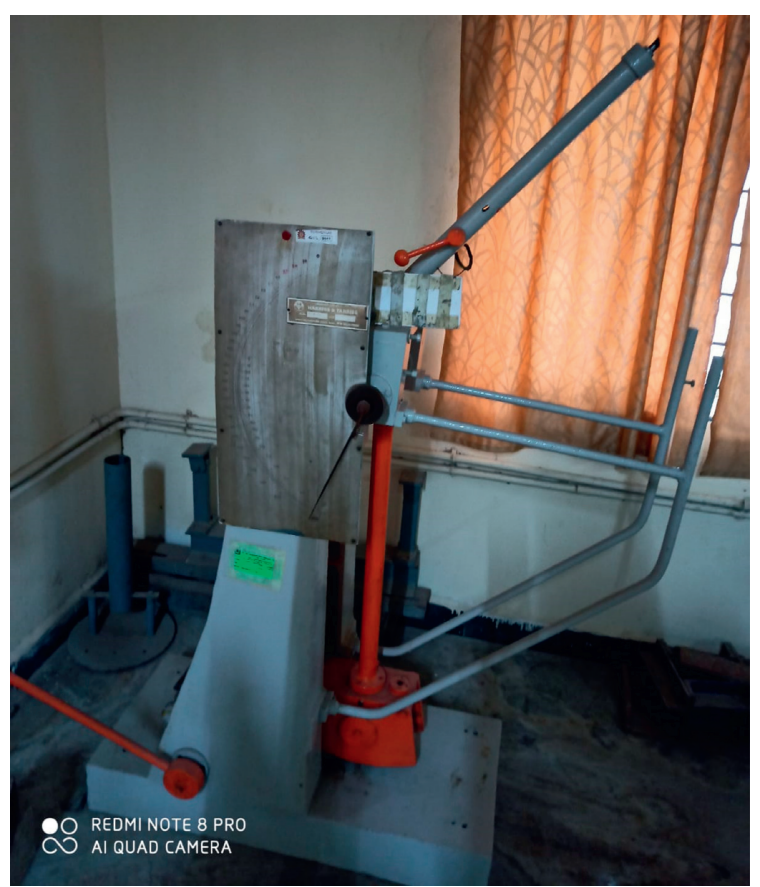

Figure 2: Impact tester.

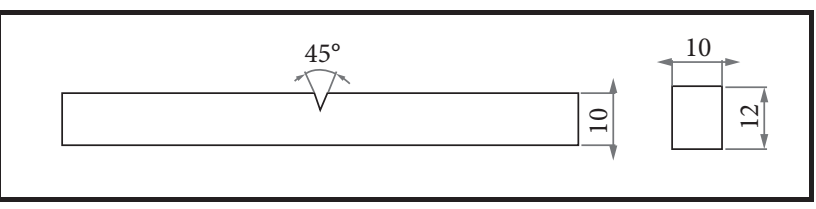

Figure 3: Schematic image of the impact sample.

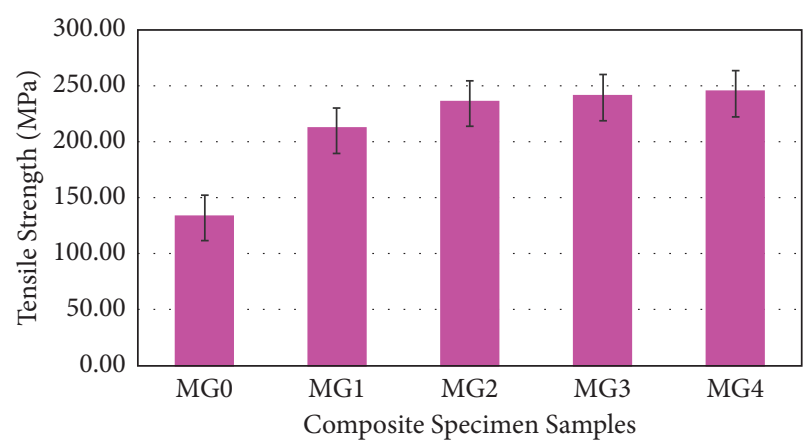

FIgURE 4: Tensile strength variation of composite specimens.

particles to align in a random orientation, which did not change in response to the applied tensile loads. Additional investigation is required to better understand the variation in Young's modulus in the peak loading condition with nanoeggshell particles' content. Since there is a greater amount of nanoeggshell particles in the composition, the ductility of the $\mathrm{Mg}$ alloy/nanoeggshell particle composite is drastically increased, and it still fits within the elongation limits for many applications. Ductility may have improved because there are more void nucleation sites due to the inclusion of nanoeggshell particles, resulting in a lower fracture strain.

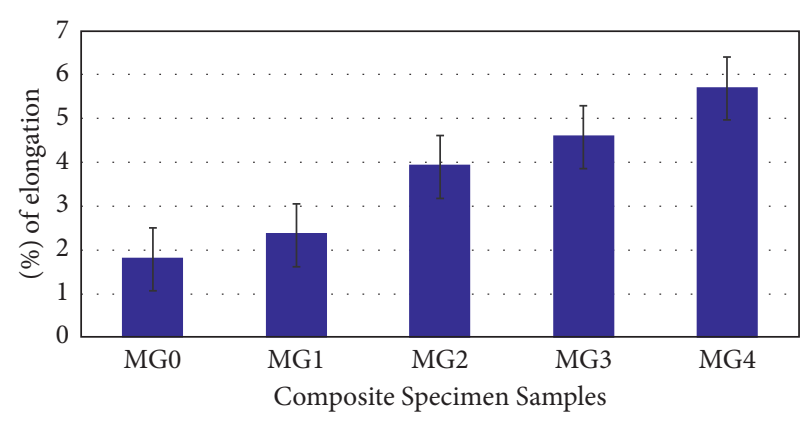

FIgURE 5: Variation on elongation percentage of composite specimens.

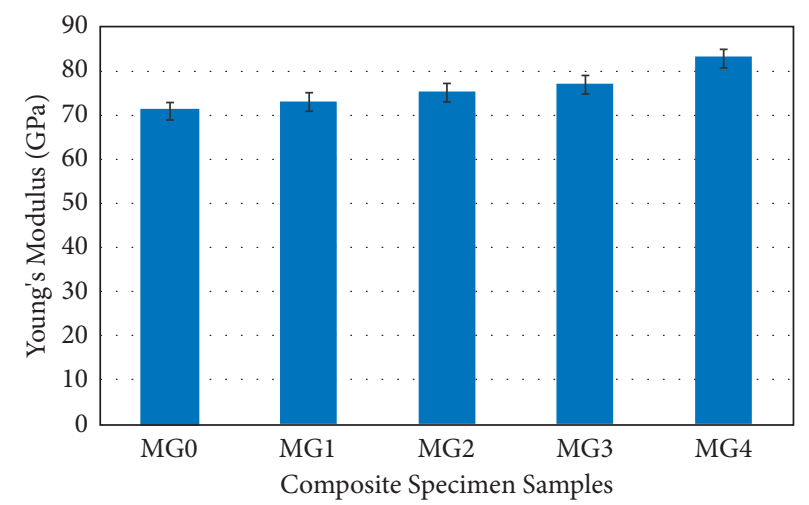

FIgURE 6: Variation on Young's modulus of composite specimens.

4.3. Yield Strength. Figure 7 shows how variations in yield tensile strengths are affected by $\mathrm{Mg}$ alloy and nanoeggshell particles' content. The MG1, MG2, MG3, and MG4 samples that contain nanoeggshell particle-reinforced composite specimens have the highest yield strength (MG0).

This boost from $93 \mathrm{MPa}$ (with no nanoeggshell particles) to $131 \mathrm{MPa}$ represents a boost in tensile strength (Mg alloy with 4 wt. percent of nanoeggshell particles). While improvements in yield strength ( $29 \%$ better) were due to the reinforcement effect of nanoeggshell particles, the strengthening of strengths (yield) was caused by the reinforcement effect of eggshell particles. Based on the findings of the present study, it can be inferred that the mechanical strength of $\mathrm{Mg}$ alloy, reinforced with nanoeggshell particles, gets stronger when compared to the studies conducted by other researchers. Concerning the yield strength of the magnesium alloy AZ31, the contributions of different reinforcements are considered, which include the addition of the nanoeggshell particle-reinforced composites.

4.4. Compressive Strength. A compression test was carried out using ASTM standards to understand the material's compressive properties. Every time the materials were reinforced, a specified amount was cut and machined at three different locations according to ASTM standards. Compression test results were recorded and plotted against the composite's reinforcement percentage. It can be concluded from Figure 8 that the compressive strength of the composite material increases with reinforcement and 


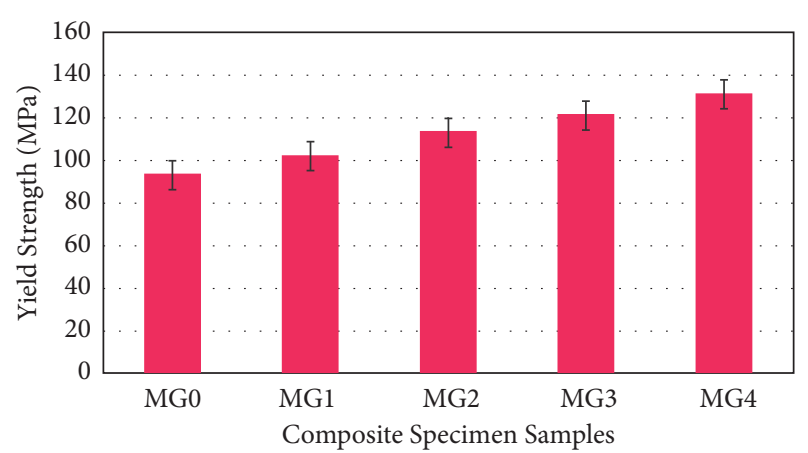

FIGURE 7: Variation on the yield strength of composite specimens.

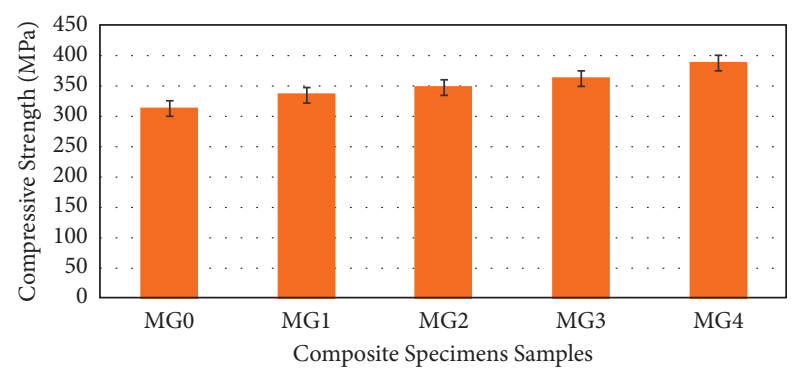

FIgURE 8: Variation on compressive strength of composite specimens.

increases quickly for a moderate amount of reinforcement. Using base magnesium alloy as a baseline, the strength of the composites gradually improves to $24.36 \%$.

4.5. Microhardness. AZ31 magnesium alloy and composite materials were both tested in the hardness test, ASTM E38499, to understand the effect of nanoeggshell particles in the magnesium matrix. Micro Vickers hardness test results show that the composite material was impacted by a $400 \mathrm{~g}$ load for 50 seconds with an $8 \mathrm{~mm}$ steel ball indenter. Five locations on the material were tested, and the results were plotted and represented as the composite's overall hardness. The hardness of the composite, which is shown in Figure 9, increases to 29.63 as opposed to the magnesium matrix.

The microhardness test results are shown in Figure 9. A pure AZ31 alloy composite specimen (MG0) was found to have a microhardness of $76 \mathrm{HV}$. Monolithic magnesium traditionally has microhardness in the range of $35-55 \mathrm{HV}$. Significant improvement in the properties of the magnesium alloy can be attributed to the solid solution strengthening of zinc in the melt in the presence of zinc as an alloying element. A monotonically increasing effect was observed after the addition of nanoeggshell particles. While all four composites show $88,96,108$, and $114 \mathrm{HV}$ in microhardness, MG1 has $1 \mathrm{wt}$ \% nanoeggshell percentage, MG2 has $2 \mathrm{wt} . \%$ nanoeggshell percentage, MG3 has 3 wt.\% nanoeggshell percentage, and MG4 has $4 \mathrm{wt}$ \% nanoeggshell percentage. Using this enhancement, you can now see the difference between soft nanoeggshell particles and hard nanoeggshell particles, which results in improved grain size and resistance to localized deformation. Tribo measurements should not be

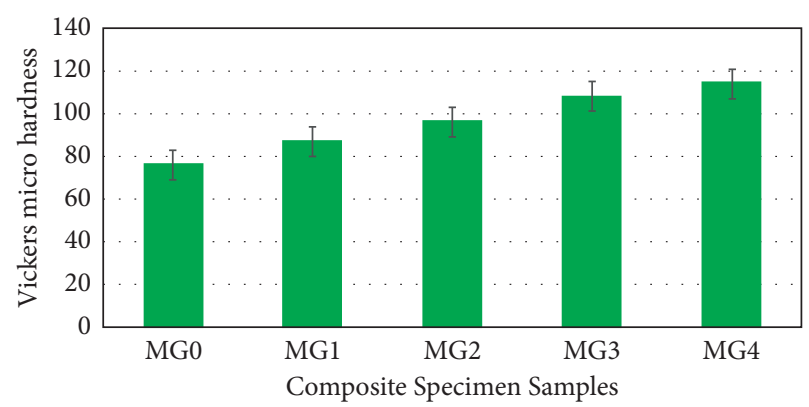

Figure 9: Variation on Vickers microhardness of composite specimens.

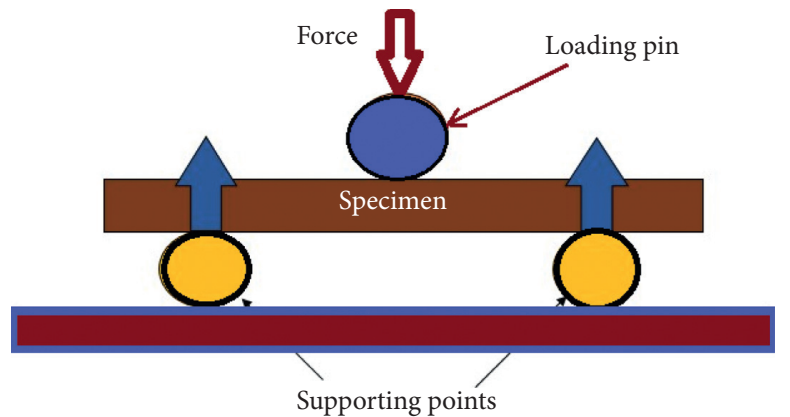

FIgURE 10: Schematic image of the flexural test setup.

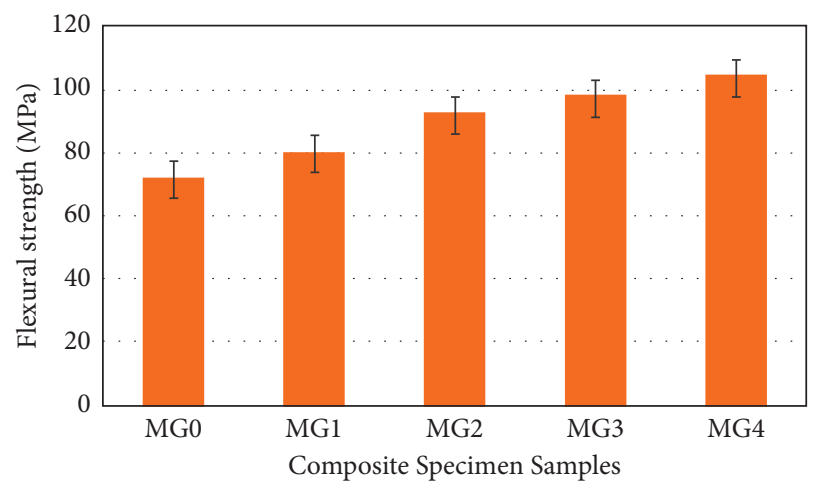

FIgURE 11: Variation on flexural strength of composite specimens.

confused with materials' hardness as an indicator of tribological response.

4.6. Flexural Strength. The three-point bend test was developed to study the material's bending behaviour according to ASTM standards. With each reinforcment, the prescribed amount was divided into three portions, which were then milled and machined at three separate locations according to ASTM standards. Flexural test arrangement is shown in Figure 10. After the value was plotted versus the percentage of reinforcement from the three-point flexural testing machine, the values were recorded. The composite's flexural strength will increase when the reinforcement intensity increases, as shown in Figure 11. Composites' strength was found to improve gradually to $30.89 \%$ when compared to the base magnesium alloy. 


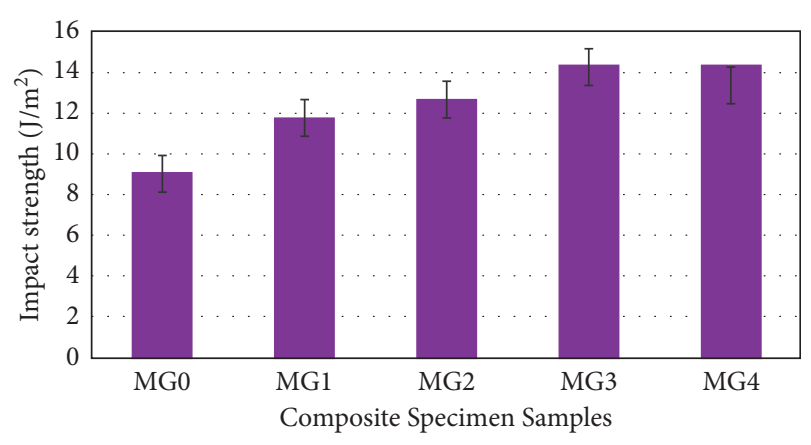

FIGURE 12: Variation on impact strength of composite specimens.

4.7. Impact Strength. To comply with ASTM standards, Charpy impact testing was required. The size we used for the test was $55 \times 10 \times 10 \mathrm{~mm}$, with a $2 \mathrm{~mm}$ depth and the standard angle. The composites were divided into three groups, and the impact toughness of each was then investigated. In Figure 12, it was discovered that impact strength increases steadily with the percentage of nanoeggshell particles, then plateaus, and declines at levels of 1 to 3 percent of composite oxidation.

\section{Conclusions}

Based on the experimental studies, the following findings were drawn: the pure magnesium alloy AZ31 $(0,1,2,3$, and 4 wt.\% of nanoeggshell particle-reinforced composite specimens) was found to have the following properties: after developing an AZ31 magnesium alloy with nanoeggshell particle-reinforced composites, the particles were dispersed evenly throughout the alloy. When compared to AZ31 magnesium alloy, which was interesting, reinforced material had better results. A few early findings of the experimental phase indicated that the metal matrix composite did not include any intermetallic phase. AZ31 alloy was changed by the addition of nanoeggshell particles. The composite is typically stronger because of the more intricate texture. There is a positive correlation between the nanoeggshell particle hybrid ratio and overall strengthening (96:04). Hybrid ratios that are large produce the most robust hybrid composites. The new model agrees with the experimental data very well.

\section{Data Availability}

The data used to support the findings of this study are included within the article. Further data or information is available from the corresponding author upon request.

\section{Conflicts of Interest}

The authors declare that there are no conflicts of interest regarding the publication of this article.

\section{Acknowledgments}

The authors appreciate the support from Wolaita Sodo University, Ethopia. The authors thank the Bharath Institute of Higher Education and Research, Chennai, and E.G.S. Pillay Engineering College, Nagapattinam, for providing technical assistance to complete this experimental work.

\section{References}

[1] S. Raja, U. M. Kumar, S. Mathivanan et al., "Mechanical and microstructural properties of graphene reinforced magnesium composite," Materials Today Proceedings, vol. 44, pp. 3571-3574, 2021.

[2] W.-J. Li, K.-K. Deng, X. Zhang et al., "Microstructures, tensile properties and work hardening behavior of $\mathrm{SiCp} / \mathrm{Mg}-\mathrm{Zn}-\mathrm{Ca}$ composites," Journal of Alloys and Compounds, vol. 695, pp. 2215-2223, 2017.

[3] S.-J. Huang and A. N. Ali, "Effects of heat treatment on the microstructure and microplastic deformation behavior of $\mathrm{SiC}$ particles reinforced AZ61 magnesium metal matrix composite," Materials Science and Engineering: A, vol. 711, pp. 670-682, 2018.

[4] S. L. Xiang, M. Gupta, X. J. Wang, L. D. Wang, X. S. Hu, and $\mathrm{K}$. $\mathrm{Wu}$, "Enhanced overall strength and ductility of magnesium matrix composites by low content of graphene nanoplatelets," Composites Part A: Applied Science and Manufacturing, vol. 100, pp. 183-193, 2017.

[5] M. Torabi Parizi, H. R. Ezatpour, and G. R. Ebrahimi, "High mechanical efficiency, microstructure evaluation and texture of rheo-casted and extruded AZ80-Ca alloy reinforced with processed Al2O3/GNPs hybrid reinforcement," Materials Chemistry and Physics, vol. 218, pp. 246-255, 2018.

[6] X.-F. Sun, C.-J. Wang, K.-K. Deng, K.-B. Nie, X.-C. Zhang, and X.-Y. Xiao, "High strength SiCp/AZ91 composite assisted by dynamic precipitated Mg17Al12 phase," Journal of Alloys and Compounds, vol. 732, pp. 328-335, 2018.

[7] F. Guo, D. Zhang, X. Yang, L. Jiang, and F. Pan, "Straininduced dynamic precipitation of Mg17Al12 phases in Mg$8 \mathrm{Al}$ alloys sheets rolled at $748 \mathrm{~K}, "$ Materials Science and Engineering: A, vol. 636, pp. 516-521, 2015.

[8] M. Torabi Parizi, A. Habibolahzadeh, and G. R. Ebrahimi, "Optimizing and investigating influence of manufacturing techniques on the microstructure and mechanical properties of AZ80-0.5Ca-1.5Al2O3 nanocomposite," Materials Chemistry and Physics, vol. 199, pp. 485-496, 2017.

[9] S. A. Sajjadi, H. R. Ezatpour, and M. Torabi Parizi, "Comparison of microstructure and mechanical properties of A356 aluminum alloy/Al2O3 composites fabricated by stir and compo-casting processes," Materials \& Design, vol. 34, pp. 106-111, 2012.

[10] M. R. Doddamani, S. M. Kulkarni, and Kishore, "Behavior of sandwich beams with functionally graded rubber core in three point bending," Polymer Composites, vol. 32, no. 10, pp. 1541-1551, 2011.

[11] M. L. Jayavardhan and M. Doddamani, "Quasi-static compressive response of compression molded glass microballoon/ HDPE syntactic foam," Composites Part B: Engineering, vol. 149, pp. 165-177, 2018.

[12] C. D. Garcia, K. Shahapurkar, M. Doddamani, G. C. M. Kumar, and P. Prabhakar, "Effect of arctic environment on flexural behavior of fly ash cenosphere reinforced epoxy syntactic foams," Composites Part B: Engineering, vol. 151, pp. 265-273, 2018.

[13] V. Manakari, G. Parande, M. Doddamani, and M. Gupta, "Evaluation of wear resistance of magnesium/glass microballoon syntactic foams for engineering/biomedical applications," Ceramics International, vol. 45, no. 7, pp. 9302-9305, 2019.

[14] B. Patil, B. R. Bharath Kumar, S. Bontha et al., "Eco-friendly lightweight filament synthesis and mechanical characterization of additively manufactured closed cell foams," 
Composites Science and Technology, vol. 183, Article ID 107816, 2019.

[15] G. Parande, V. Manakari, G. K. Meenashisundaram, and M. Gupta, "Enhancing the hardness/compression/damping response of magnesium by reinforcing with biocompatible silica nanoparticulates," International Journal of Materials Research, vol. 107, no. 12, pp. 1031-1099, 2016.

[16] R. Swaminathan, "Magnesium metabolism and its disorders," Clinical Biochemist Reviews, vol. 24, no. 2, pp. 47-66, 2003.

[17] A. Atrens, G.-L. Song, M. Liu, Z. Shi, F. Cao, and M. S. Dargusch, "Review of recent developments in the field of magnesium corrosion," Advanced Engineering Materials, vol. 17, no. 4, pp. 400-453, 2015.

[18] M. Gupta and W. L. E. Wong, "Magnesium-based nanocomposites: lightweight materials of the future," Materials Characterization, vol. 105, pp. 30-46, 2015.

[19] M. S. Kujur, A. Mallick, V. Manakari, G. Parande, K. S. Tun, and M. Gupta, "Significantly enhancing the ignition/compression/ damping response of monolithic magnesium by addition of Sm2O3 nanoparticles," Metals, vol. 7, no. 9, p. 357, 2017.

[20] J. Walker, S. Shadanbaz, T. B. F. Woodfield, M. P. Staiger, and G. J. Dias, "Magnesium biomaterials for orthopedic application: a review from a biological perspective," Journal of Biomedical Materials Research Part B: Applied Biomaterials, vol. 102, no. 6, pp. 1316-1331, 2014.

[21] G. Kumar Meenashisundaram, T. Hou Damien Ong, G. Parande, V. Manakari, S. Xiang, and M. Gupta, "Using lanthanum to enhance the overall ignition, hardness, tensile and compressive strengths of Mg-0.5Zr alloy," Journal of Rare Earths, vol. 35, no. 7, pp. 723-732, 2017.

[22] A. Atrens, G.-L. Song, F. Cao, Z. Shi, and P. K. Bowen, "Advances in $\mathrm{Mg}$ corrosion and research suggestions," Journal of Magnesium and Alloys, vol. 1, no. 3, pp. 177-200, 2013.

[23] J. Lan, Y. Yang, and X. Li, "Microstructure and microhardness of $\mathrm{SiC}$ nanoparticles reinforced magnesium composites fabricated by ultrasonic method," Materials Science and Engineering: A, vol. 386, no. 1-2, pp. 284-290, 2004.

[24] G. Cao, H. Choi, J. Oportus, H. Konishi, and X. Li, "Study on tensile properties and microstructure of cast AZ31D/AlN nanocomposites," Materials Science and Engineering: A, vol. 494, no. 1-2, pp. 127-131, 2008.

[25] S. F. Hassan and M. Gupta, "Development of high performance magnesium nanocomposites using solidification processing route," Materials Science and Technology, vol. 20, no. 11, pp. 1383-1388, 2004.

[26] W. L. E Wong and M. Gupta, "Simultaneously improving strength and ductility of magnesium using nano-size SiC particulates and microwaves," Advanced Engineering Materials, vol. 8, no. 8, pp. 735-740, 2006.

[27] C. Goh, J. Wei, L. Lee, and M. Gupta, "Properties and deformation behaviour of Mg-Y2O3 nanocomposites," Acta Materialia, vol. 55, no. 15, pp. 5115-5121, 2007.

[28] S. F. Hassan and M. Gupta, "Development and characterization of ductile $\mathrm{Mg} / \mathrm{Y} 2 \mathrm{O} 3$ nanocomposites," Journal of Engineering Materials and Technology, Transactions of the ASME, vol. 129, no. 3, pp. 462-467, 2007.

[29] K. S. Tun and M. Gupta, "Improving mechanical properties of magnesium using nano-yttria reinforcement and microwave assisted powder metallurgy method," Composites Science and Technology, vol. 67, no. 13, pp. 2657-2664, 2007.

[30] K. K. Deng, K. Wu, Y. W. Wu, K. B. Nie, and M. Y. Zheng, "Effect of submicron size $\mathrm{SiC}$ particulates on microstructure and mechanical properties of AZ91 magnesium matrix composites," Journal of Alloys and Compounds, vol. 504, no. 2, pp. 542-547, 2010.

[31] G. Parande, V. Manakari, S. D. S. Kopparthy, and M. Gupta, "Utilizing low-cost eggshell particles to enhance the mechanical response of $\mathrm{Mg}-2.5 \mathrm{Zn}$ magnesium alloy matrix," Advanced Engineering Materials, vol. 20, no. 5, Article ID 1700319, 2018.

[32] S.-Y. He, Y. Sun, M.-F. Chen, D.-B. Liu, and X.-Y. Ye, "Microstructure and properties of biodegradable $\beta$-TCP reinforced Mg-Zn-Zr composites," Transactions of Nonferrous Metals Society of China, vol. 21, no. 4, pp. 814-819, 2011.

[33] A. Chaithanyasai, P. R. Vakchore, and V. Umasankar, "The micro structural and mechanical property study of effects of EGG SHELL particles on the Aluminum 6061," Procedia Engineering, vol. 97, pp. 961-967, 2014.

[34] S. B. Hassan and V. S. Aigbodion, "Effects of eggshell on the microstructures and properties of Al-Cu-Mg/eggshell particulate composites," Journal of King Saud University - Engineering Sciences, vol. 27, no. 1, pp. 49-56, 2015. 